\title{
The Effect of the Job Environment of Accounting Managers on Job Satisfaction
}

\author{
Lee, Byung-Sam ${ }^{1}$ and Hong, Soon-Bok ${ }^{2 *}$ \\ ${ }^{1}$ Department of Business Administration, Tongmyong University, Busan, Korea \\ 2*Department of Business Administration, Tongmyong University, Busan, Korea \\ ${ }^{1}$ sejin5052@nate.com, ${ }^{2 *}$ hong6601@hanmail.net
}

\begin{abstract}
This study aims to investigate and analyze the effects of the general environment and job environment on job satisfaction of accounting personnel in order to find out whether the job environment recognized by accounting personnel is significantly explained about job satisfaction of employees. To this end, a survey is conducted on the person carrying out accounting post in active service. In addition, the empirical analysis for the results of the study was conducted by SPSS Ver.25.0. Demographic analysis, reliability analysis, validity analysis, correlation analysis, multiple regression analysis and moderating regression analysis were subsequently conducted through the statistics package program. Based on the results of the empirical analysis, this study hopes that the results can be used as basic data to improve job satisfaction to better the job environment of accounting personnel and to improve job satisfaction through it. Also, based on the results of this study, the limitations of the study and future research directions are to be suggested. This study attempted to approach job satisfaction and enthusiasm to duty, which have physical and psychological characteristics, from an integrated perspective. The academic implication of this study lies in investigating the relationship between the job environment and the importance of job enthusiasm on the part of persons in charge through empirical analysis. In addition, this study proves that companies should make continuous efforts to maintain a reasonable and fair reward system for the work performance and to improve the physical environment for the job environment.
\end{abstract}

Keywords: Accounting, Job environment, Job satisfaction, Job passion

\section{Introduction}

Recently, many companies are not only seeking to share knowledge and collaborate among employees, but also pursuing a change to create flexible work environment as well as space efficiency. This change, which companies are paying more attention to after the implementation of the 52-hour workweek, is to ensure the quality of work life so that employees can work more efficiently in work-life balance. It has been studied by many scholars that various characteristics of work environment affect office workers' satisfaction and work productivity.[1]

Therefore, this study aims to investigate and analyze the effects of the general environment and the job environment on job satisfaction of accounting personnel in order to find out whether the job environment recognized by accounting personnel is significantly explained to the job satisfaction of employees. Based on the results of the empirical analysis, this study hopes that

Article history:

Received (December 26, 2020), Review Result (January 28, 2021), Accepted (March 6, 2021) 
the improvement of the job environment of accounting personnel will be utilize as basic data for creating a stable work environment and improving job satisfaction through it. Also, based on the results of this study, the limitations of the study and future research directions are to be suggested.

\section{Theoretical background}

\subsection{Job environment}

The environment is not only a physical and psychological condition in which people interacts but also a process or external stimulus, so it determines the range that human behavior changes and determines the process and type accordingly.[2] As many studies prove that employees' efficiency and productivity are improved and the satisfaction and loyalty of the employees to the company increased with environment improved, the job environment is considered important in terms of corporate management. Recently, companies have been creating an atmosphere to create a job environment in which office workers are more immersed in their work and maximize work efficiency.[3] The job environment refers to the overall physical and psychological environment that is designed to enable the organizational members to perform their duties smoothly.[4] In addition, the work environment is a concept that includes interaction with colleagues, organizational culture, policy, and physical environment which affects the work that the staff has perceived as his or her job from an institution, organization, or individual.[5].

This study also intends to use them in the categories of human environment, physical environment, and reward system.[6] First, human environment is a very important part of the job environment. The supervisor plays a role in forming an efficient working group and stimulating individual members of the group in charge to make the members achieve the maximum performance. The interaction between colleagues in the working group is more dynamic than the incentive system or control of manager and the adaptation to the working environment plays an important role.[7] Second, Bitner (1992) defined the physical environment as an objective and physical factor that the company can control, and divided the components into facilities-related elements and other elements. Park Young-Hee \& Rah JoongDoug (2011) divided physical environment into work environment, maintenance of facilities, space for employees to rest and amenities, and employee welfare.[8] Third, reward refers to the factors that can induce employees to continue to settle in the organization, which means all kinds of monetary benefits, non-financial benefits, and other benefits in return for his work that employees maintain employment relations with managers or operators.[9]

\subsection{Job satisfaction}

Job satisfaction is a positive emotional state that occurs through the evaluation of the job itself.[10] The concept of job satisfaction in the early days was defined as an attitude derived from the emotional state obtained in relation to individual job activities. Then, McCormick \& Tiffin (1974) defined job satisfaction as positive emotional state that individuals experience according to their attitudes, values, beliefs, desires, etc. in relation to their job.[11] As the studies of definitions and arguments put it, as a sense of satisfaction or achievement felt through job performance which is closely related to individuals' need satisfaction, job satisfaction is a pleasant and good emotional state on their jobs.

Overall put together on the whole, the meaning of job satisfaction is broad, including personal and subjective thoughts, and the difference in job satisfaction can be different 
depending on the characteristics of each individual. However, differences in opinions may occur depending on each evaluation, method, and design, but they can also be expressed as job satisfaction. The analysis of the factors of job satisfaction derived from many scholars shows that the factors that are common are found: Job satisfaction is determined by various common factors such as wage, promotion opportunity, job condition, job environment, relationship with boss and colleagues and self-achievement.

\subsection{Job passion}

In the previous studies on job passion, Piccolo et al. (2010) suggested that leaders with strong ethical commitment can influence autonomy. Therefore, autonomy is an important predictor of motivation and passion, and the increase of control and autonomy through the sharing of power of ethical leadership is expected to have a positive (+) relationship with harmonious passion rather than obsessive passion.[12] Chah Dong-wook et al.(2016) showed positive relationship between the boss's ethical leadership and the subordinates' harmonious passion and organizational identification, but there was no correlation with the subordinates' job stress. And the ethical leadership of the boss had a positive effect on the organizational identification of the subordinates and a negative effect on the job stress of the subordinates through the harmonious passion of the subordinates. Specifically, harmonious passion played a partial mediating role in the relationship between ethical leadership and organizational identification, and played a full mediating role in the relationship between ethical leadership and job stress.[13]

The implication of the results of previous studies on job passion is that employees with job passion will be satisfied and happy with their work, which makes them immersed with attachment to their work. Furthermore, this passion will be conveyed in the relationship with customers, and the satisfaction felt by customers will soon be transferred to their satisfaction. Happy employees with passion will deliver happiness to customers in interaction with customers, and the impressions experienced by customers will be circulated to satisfaction to employees again [14].

\section{Research design and the empirical analysis}

\subsection{Research design and hypothesis}

This study is to verify the moderating effect of job passion in the relationship between job environment (an independent variable of accounting worker) and job satisfaction (an independent variable and a dependent variable). For this purpose, a survey was conducted for 31 days from August 1, 2020 to August 31, 2020 for the employees in charge of accounting work at companies located in Seoul and metropolitan cities.

The questionnaire was written by personal self-writing method by face-to-face method. The questionnaire was distributed to 400 copies and 364 copies were collected. Among the collected questionnaires, 351 questionnaires were used for the final study except 13 questionnaires that were unfaithful.

To achieve the purpose of this study, a research model such as [Figure 1] is presented based on literature research and previous studies.

In addition, the premise that the job environment will have a significant impact on accounting workers' job satisfaction and the proposition that job enthusiasm will play a moderating role in the relationship between job environment and job satisfaction. The hypothesis according to this is set up as follows and verified.

Hypothesis 1 The job environment will have a significant effect on job satisfaction. 
1-1 The human environment of the job environment will have a significant effect on job satisfaction.

1-2 The physical environment of the job environment will have a significant effect on job satisfaction.

1-3 The reward system of job environment will have a significant effect on job satisfaction.

Hypothesis 2 Job passion will play a role of moderating the relationship between job environment and job satisfaction.

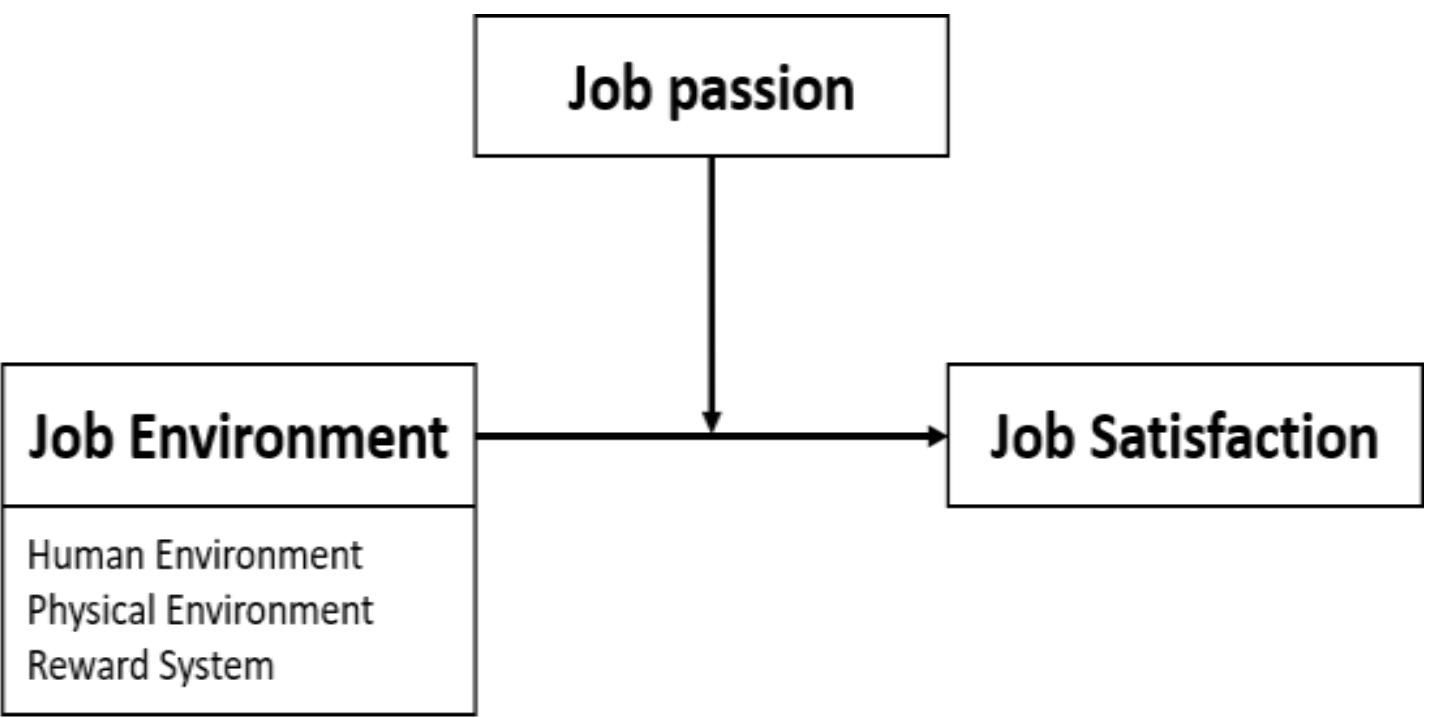

Figure 1. Research Model

\subsection{Validity and reliability}

The KMO measurement of the research variables was .892, Bartlett's sphere formation test value was 5683.873 , and the significance probability was .0000 , which turns out to be suitable for factor analysis by rejecting the null hypothesis as [Table 1] shows. The reliability criteria for chonbach's were 0.844 for human environment, 0.829 for physical environment, 0.843 for reward system, 0.890 for job satisfaction, and 0.877 for job enthusiasm, which were higher than .7 and were internally consistent.

The factor analysis showed that all the scales used for measuring variables have appropriate convergence and discriminant validity. Also, the reliability level of each variable was generally high, which was found to be appropriate for analysis in this study.

Table 1. Factor analysis of research variables

\begin{tabular}{|c|c|c|c|c|c|}
\hline \multicolumn{2}{|c|}{ Variable } & $\begin{array}{c}\text { Factor Loading } \\
\text { Value }\end{array}$ & Eigen Value & $\begin{array}{c}\text { Explanatory Distribution } \\
(\%)\end{array}$ & Reliability $(\alpha)$ \\
\hline \multirow{3}{*}{$\begin{array}{c}\text { Job } \\
\text { Environment }\end{array}$} & $\begin{array}{c}.791 \\
\text { Environment }\end{array}$ & $\begin{array}{c}.767 \\
.757\end{array}$ & 3.257 & 11.231 & .844 \\
\hline
\end{tabular}




\begin{tabular}{|c|c|c|c|c|}
\hline & .636 & & & \\
\hline $\begin{array}{c}\text { physical } \\
\text { Environment }\end{array}$ & $\begin{array}{l}.730 \\
.704 \\
.691 \\
.674 \\
.648\end{array}$ & 3.487 & 12.023 & .829 \\
\hline $\begin{array}{l}\text { Reward } \\
\text { System }\end{array}$ & $\begin{array}{l}.798 \\
.708 \\
.676 \\
.486\end{array}$ & 2.900 & 10.001 & .843 \\
\hline Job Satisfaction & $\begin{array}{l}.796 \\
.744 \\
.725 \\
.712 \\
.651 \\
.525\end{array}$ & 4.124 & 14.222 & .890 \\
\hline Job Passion & $\begin{array}{l}.790 \\
.753 \\
.750 \\
.697 \\
.691\end{array}$ & 4.486 & 16.157 & .870 \\
\hline Bartlett's test & yer-O & e of sa & uacy $=.8$ & \\
\hline
\end{tabular}

\subsection{Hypothesis verification}

The results of hypothesis 1 are as follows: First, the relationship between human environment and job satisfaction was found to have no statistically significant effect as the nonstandardization coefficient of human environment on job satisfaction was 0.063 . Therefore, hypothesis 1-1 was not supported.

Second, the relationship between physical environment and job satisfaction was statistically significant at the significance level $\mathrm{p}<.001$, with the non-standardization coefficient of physical environment for job satisfaction of 0.236 . Therefore, the physical environment had a significant positive effect on job satisfaction, and hypothesis 1-2 was supported.

Third, the relationship between reward system and job satisfaction was statistically significant at the significance level $\mathrm{p}<.001$, with the non-standardization coefficient of compensation system for job satisfaction being 0.499 . Therefore, the reward system had a significant positive effect on job satisfaction, and hypothesis 1-3 was supported.

The result of verifying the moderating effect of job passion in the relationship between job environment and job satisfaction.

The result of analysis shows that the overall explanatory power is $40.1 \%(\mathrm{R} 2=.401)$ and $\mathrm{F}=70.387(\mathrm{p}<.001)$, which is statistically significant.

In [Model 2], job enthusiasm was put into the moderating variable, the explanatory power was $48.9 \%(\mathrm{R} 2=.489)$ and $\mathrm{F}=77.430(\mathrm{p}<.001)$. The explanatory power increased by $8.8 \%$ and the $\mathrm{F}$ value increased by $7.043 \%$ compared to [Model 1].

In the case of [Model 3], the sub-variables of job environment such as human environment, physical environment, and reward system were put into interaction with job enthusiasm. In Model 3, the explanatory power was $49.9 \%(\mathrm{R} 2=.499)$ and $\mathrm{F}=46.385(\mathrm{p}<.001)$. Compared to 
The Effect of the Job Environment of Accounting Managers on Job Satisfaction

[Model 2], the explanatory power decreased by $1.0 \%$ and the F value decreased by $31.045 \%$, but it turned out to be statistically significant.

\section{Conclusion}

This study aims to empirically investigate the relationship between accounting staff's job environment and their job satisfaction and also aims to prove that there is the moderating effect of job enthusiasm. This is considered to have a great practical meaning in that it provides implications for the improvement and securing of the job environment of the company and the enhancement of the efficiency of the company's work.

The results of the empirical analysis of this study are as follows: First, physical environment and reward system among the factors of job environment had a significant positive effect on accounting staff's job satisfaction. Hypothesis 1-2 and Hypothesis 1-3 were supported, however, the human environment was not statistically significant, so Hypothesis 1-1 was rejected.

Despite the results of this study, this study has several limitations. Through the limitations of this study, I would like to suggest future research directions. The generalization of the results of the study is somewhat unreasonable by selecting sample areas centered on large cities. In the follow-up study, if the study including those who are in charge of accounting work in small and medium cities is done out of the sample area limited to large cities, the results of the study can be generalized.

\section{References}

[1] S. Y. Park, "A study on effect of work environmental characteristics of office on work efficiency and job satisfaction," M.S Thesis, Kyung-Hee University, Seoul (2019)

[2] S. Y. Choi, "The effect of environmental change in employment on food service employees on job instability and job stress: Focusing on the moderating effects of ego-resilience," Korean Journal of Tourism Research, vol.35, no.8, pp.47-66, (2020)

[3] S. E. Yoo, "The relationships of office environment features and workers' productivity in open plan office," Ph.D. Thesis, Yon-Sei University, Seoul (2012)

[4] J. Y. Lee and J. O. Ko, "The effects on turnover intention of infant-care teacher's working environment and job satisfaction," Journal of Korean Child Care and Education, vol.11, no.1, pp.63-82, (2015) 1738-9496 (pISSN)

[5] Y. M. Lee, "Facet-based and facet-only job satisfaction measures in Korea," Human Resource Management Study, vol.15, no.4, pp.147-185, (2008)

[6] G. M. Nam and H. S. Gwen, "The effects of working environment on client-oriented tendency of care workers in Long," Journal of the Korean Academy of Health and Welfare for Elderly, no.58, pp.253-280, (2012)

[7] S. B. Lee, "A study on how the work environment of the employees working at mental recuperation welfare institutions effects job satisfaction,” Ph.D Thesis Han-Seung University, Seoul, (2007)

[8] Y. H. Park and J. D. Rah, "An influences which environmental factors of care providers has on self-efficacy and job satisfaction," Journal of the Korean Academy of Health and Welfare for Elderly, vol.3 no.2, pp.12-22, (2011)

[9] Y. S. Lee and S. K. Moon, "A study on the effect of work environment and system on job satisfaction of nursing care workers," Journal of the Korean Gerontological Society, vol.32, no.1, pp.305-321, (2012)

[10] E. J. Lee and E. S. Lee, "Job stress and job satisfaction of the nurses in comprehensive nursing service units and the nurses in general units," Journal of the Korea Convergence Society, vol.11, no.3, pp.351-360, (2020)

[11] E. J. McCormick and J. Tiffin, "Industrial psychological, (6th ed)," Prentice Hall, pp.298-299, (1974) 
[12] R. F. Piccolo, R. Greenbaum, D. N. Den Hartog, and R. Folger, "The relationship between ethical leadership and core job characteristics," Journal of Organizational Behavior, vol.31, pp.259-278, (2010) DOI: 10.1002/job.627|

[13] D. O. Chah, J. H. Lee, I. M. Heo, and Y. J. Kim, "The effects of ethical leadership on subordinates' organizational identification and job stress: The mediating role of subordinates' harmonious passion," Journal of the Korean Content Association, vol.16, no.6, pp.761-773, (2016) DOI: 10.5392/JKCA.2016.16.06.761

[14] S. H. Kim, “Are happier salespersons more customer-oriented?” Korean Management Review, vol.36, no.4, pp.855-896,(2007) DOI: 10012621\&local_id=10018347 
The Effect of the Job Environment of Accounting Managers on Job Satisfaction

This page is empty by intention. 